\title{
Serum-derived bovine immunoglobulin/protein isolate in the alleviation of chemotherapy-induced mucositis
}

\author{
Emma Bateman $^{1} \cdot$ Eric Weaver ${ }^{2} \cdot$ Gerald Klein $^{2} \cdot$ Anthony Wignall $^{1}$. \\ Belinda Wozniak $^{1} \cdot$ Erin Plews $^{1} \cdot$ Bronwen Mayo $^{3} \cdot$ Imogen White ${ }^{4} \cdot$ Dorothy Keefe $^{1,5}$
}

Received: 3 March 2015 / Accepted: 8 June 2015 / Published online: 17 June 2015

(C) The Author(s) 2015. This article is published with open access at Springerlink.com

\begin{abstract}
Background Gastrointestinal (GI) mucositis caused by chemotherapy is associated with diarrhoea and intestinal barrier disruption caused by apoptosis, immune dysfunction and microbiome alterations. Serum-derived bovine immunoglobulin/protein isolate (SBI) has been shown to manage HIV-associated enteropathy and irritable bowel syndrome with diarrhoea (IBS-D). We investigated in a rat model whether SBI was effective in alleviating symptoms of irinotecan-induced GI mucositis.

Methods Animals were gavaged with 250 or $500 \mathrm{mg} / \mathrm{kg}$ of SBI twice daily for 4 days, before intraperitoneal administration of $200 \mathrm{mg} / \mathrm{kg}$ irinotecan. Twice daily gavaging of SBI continued for 6 days post-irinotecan. Animals were monitored for bodyweight changes and incidence of diarrhoea and clinical symptoms of stress. Tissues and blood samples were collected at necropsy $6 \mathrm{~h}$, and 2, 4 and 6 days post-irinotecan. H\&E-stained colon and jejunum were analysed for histological damage.
\end{abstract}

\section{Emma Bateman}

emma.bateman@adelaide.edu.au

1 Mucositis Research Group, School of Medicine, Faculty of Health Sciences, University of Adelaide, Level 4 Hanson Institute Building, Frome Road, Adelaide, SA 5000, Australia

2 Entera Health Inc, Cary, NC, USA

3 School of Pharmacy and Medical Sciences, University of South Australia, Adelaide, SA, Australia

4 School of Medical Sciences, Faculty of Health Sciences, University of Adelaide, Adelaide, SA, Australia

5 SA Cancer Service, Royal Adelaide Hospital, Adelaide, SA, Australia
Results The overall incidence, severity and duration of diarrhoea, and clinical symptoms of mucositis were decreased in irinotecan-treated animals that had received SBI. Animals receiving $500 \mathrm{mg} / \mathrm{kg} \mathrm{SBI}$ also tended to lose less bodyweight than animals treated only with irinotecan $(P>0.10)$. SBIgavaged animals had less pronounced irinotecan-induced changes in neutrophil $(P=0.04959)$ and lymphocyte $(P=$ $0.0035)$ levels, and lower tissue damage scores than those receiving irinotecan alone $(P<0.0001)$.

Conclusions Twice daily oral gavage of SBI was welltolerated and reduced the incidence, severity and duration of irinotecan-induced mucositis. SBI was associated with less pronounced changes in inflammatory cell levels and tissue damage to colon and jejunum. Ongoing experiments aim to investigate the mechanisms of SBI-associated gastrointestinal protection.

Keywords Mucositis $\cdot$ Animal model $\cdot$ Serum-derived bovine immunoglobulin/protein isolate (SBI) $\cdot$ Medical food .

Enteropathy

\section{Introduction}

Chemotherapy-induced gastrointestinal mucositis (CIGM) can not only necessitate treatment delay or cessation but also, more importantly, represent a significant burden to healthcare costs and patient quality of life [1]. Symptoms include diarrhoea, abdominal pain and weight loss and are a direct result of damage to the epithelial layer of the gut, which increases permeability, induces inflammation and ulceration, and prevents adequate nutrient uptake. Alterations to the gut microbiome are also associated with mucositis, which can further drive the inflammatory state [2,3]. At present, treatment for mucositis is supportive only; new interventions 
intended to prevent and/or reduce mucositis are being investigated and include growth factors, anti-inflammatories, nutritional supplements and medicinal foods [4].

Oral administration of serum-derived immunoglobulin, derived from human or animal serum or plasma, has been shown to improve symptoms of disease states with an inflammatory basis, such as viral gastroenteritis in children [5], malnourishment in children [6], weaning in pigs [7], irritable bowel syndrome with diarrhoea (IBS-D) $[8,9]$ and HIVinduced enteropathy [10]. Serum-derived bovine immunoglobulin/protein isolate (SBI) is obtained through the spray-drying of bovine plasma and is available commercially as EnteraGam ${ }^{\mathrm{TM}}$ (Entera Health Inc., Cary, NC, USA), which is regulated by the FDA as a medical food in the management of IBS-D [8, 9] and HIV-associated enteropathy [10].

The aforementioned enteropathic conditions are associated with abdominal pain, weight loss, malabsorption and diarrhoea, and as such have a similar symptom profile to CIGM. With this in mind, the rationale for the current study was to determine whether SBI had similar positive effects on irinotecan-induced GI mucositis in a Dark Agouti rat model.

\section{Methods and materials}

\section{Animals}

Animal work complied with the National Health and Medical Research Council (Australia) Code for the Care and Use of Animals for Scientific Purposes (8th edition, 2013). Ethics approval was obtained from both University of Adelaide and SA Pathology. Animals were group-housed (four animals/ cage) in standard conditions of light and dark cycles and had food and water available ad libitum.

Female Dark Agouti rats ( $n=192)$ of $150-180 \mathrm{~g}$ were randomly assigned to treatment groups. Our models of chemotherapy-induced mucositis focus on growing (nonadult) animals, as younger animals are more responsive to chemotherapy.

\section{Serum-derived bovine immunoglobulin/protein isolate}

SBI was provided by Entera Health Inc. as a $>90 \%(w /$ $w$ ) protein powder, comprised of $>50 \%$ immunoglobulin $\mathrm{G}(\mathrm{IgG})$, and a mixture of other serum proteins similar to that found in milk and colostrum. Additional ingredients are dextrose and trace amounts of sunflower lecithin. SBI is free of milk products (lactose, casein, whey), gluten, dye and soy, and is manufactured in accordance with current Good Manufacturing Practice (cGMP) for medical foods [9]. Powdered SBI was mixed with water for dosing as recommended in the prescribing information, and the doses used in this study (250 and $500 \mathrm{mg} / \mathrm{kg}$ ) were based around the daily human equivalent dose $(\sim 5$ $10 \mathrm{~g} /$ day $[10,8,9])$; average gavage volume was 1.5 $2 \mathrm{~mL}$.

\section{Experimental plan}

On experimental day 4 , animals were orally gavaged twice daily (at 8 a.m. and 3 p.m.) with either 250 or $500 \mathrm{mg} / \mathrm{kg}$ of SBI, or an equivalent volume of $0.09 \%$ saline. This was continued for 11 days. On day $0,200 \mathrm{mg} / \mathrm{kg}$ of irinotecan was administered intraperitoneally to appropriate groups, with $0.01 \mathrm{mg} / \mathrm{kg}$ of subcutaneous atropine to prevent a cholinergic reaction.

Animals were monitored for $6 \mathrm{~h}$ following irinotecan administration for clinical signs of stress; at this time point, eight animals in each treatment group were killed. Approximately $4 \mathrm{~mL}$ of blood was collected for analysis. Animals were dissected; intestinal tissue was removed and flushed with chilled saline, and organs were removed, then all tissues were weighed and fixed in formalin. Remaining animals continued to receive twice daily oral gavage; on days 2,4 and 6 posttreatment, eight animals in each group were killed. Animals were weighed and monitored for clinical symptoms of stress and diarrhoea up to four times daily; these include piloerection, stress marks (porphyrin discharge from Harderian glands), changes in movement, temperament and posture, reduction in temperature, weight loss, and reduced food and water intake. These symptoms were scored as 0 (none), 1 (mild), 2 (moderate) or 3 (severe), and incidence data were charted. Incidence of irinotecan-induced diarrhoea was also charted for each animal, based on the following established criteria [11]: 0 (none), 1 (mild; staining around anus), 2 (moderate; staining around anus and top of hind legs) and 3 (severe; staining over legs and abdomen, often with continual oozing).

\section{Histochemical, biochemical and morphometric assessment}

All experiments were performed in a blinded fashion. Blood and serum were sent to SA Pathology (Frome Road, Adelaide) for complete blood examination (CBE) and blood biochemistry tests (MBA-20). Formalin-fixed, paraffin-embedded jejunum and colon were cut into $4-\mu \mathrm{m}$ sections and stained with haematoxylin and eosin for damage scoring, or alcian blue/periodic acid-Schiff mucin stain to assess changes in goblet cells [12]. Immunohistochemistry to detect levels of caspase-3 (apoptosis marker) and ki67 (proliferation marker) [13] was also performed on 4- $\mu \mathrm{m}$ formalin-fixed, paraffinembedded sections. Microdissection to assess tissue morphometry (villous area and crypt depth) was performed as per established protocols $[11,14]$. 


\section{Tissue damage scoring}

Histopathological changes in H\&E-stained colon and jejunum were scored according to criteria described in Table 1. Scores for each tissue section were tallied and represented as a percentage of the total score possible (20 for colon, 22 for jejunum).

\section{Statistical analyses}

$P$ values in the text represent two-way ANOVA with Bonferroni post hoc testing, unless specified otherwise.

\section{Results}

\section{Bodyweight}

There was a clear separation in bodyweights 1 day postirinotecan administration, whereby animals receiving irinotecan lost $5 \%$ of bodyweight (approximately $10 \mathrm{~g}$ ), regardless of experimental group, compared to untreated animals (Fig. 1a, b). On day 2, this separation reached significance $(P<0.0001$, Fig. 1a, b) and continued throughout the study. While irinotecan-treated animals gavaged with $500 \mathrm{mg} / \mathrm{kg}$ SBI lost less weight than other groups, this failed to reach significance $(P=0.10$; Fig. 1a, b).

\section{Clinical signs of stress and diarrhoea}

There were no clinical symptoms in the 4-day pre-treatment period, so data are presented from day 0 onwards. Peak symptom incidence and severity in treated controls were on day 3 , with $82 \%$ of animals experiencing symptoms, $16 \%$ of these with severe symptoms (Fig. 2a). Administration of $250 \mathrm{mg} / \mathrm{kg}$ SBI reduced the overall incidence and severity of symptoms from days 1-5, with complete resolution of symptoms by day $5,11 \%$ less animals experiencing grade 3 symptoms overall and $28 \%$ less experiencing grade 2 symptoms (Fig. 2b). Administration of $500 \mathrm{mg} / \mathrm{kg} \mathrm{SBI}$ also reduced the overall incidence and severity of symptoms from days 1 to 6 , with $11 \%$ less animals experiencing grade 3 symptoms overall (Fig. 2c).

All rats receiving irinotecan developed diarrhoea, which peaked on days 3 and 4; administration of SBI reduced the overall incidence, severity and duration of irinotecan-induced diarrhoea (Fig. 2d-f). Incidence of grade 2 diarrhoea was reduced in animals gavaged with $250 \mathrm{mg} / \mathrm{kg}$ SBI (Fig. 2e) compared to treated controls (Fig. 2d) on day 0 (6 vs 9\%), day 2 (4 vs $29 \%$ ), day 3 (18 vs $19 \%$ ) and day 4 (27 vs $44 \%$ ), and incidence of grade 3 diarrhoea was reduced on day 3 (50 vs $62 \%$ ) and day 5 (14 vs $25 \%$ ). This reduction was even more pronounced in animals gavaged with $500 \mathrm{mg} / \mathrm{kg} \mathrm{SBI}$, with all diarrhoea symptoms resolving by day 5 (Fig. 2f), and a reduction in grade 2 diarrhoea compared to treated controls on day 0 (0 vs $9 \%$ ), day 2 (13 vs $29 \%$ ), day 4 (21 vs $44 \%$ ), and a reduction of grade 3 diarrhoea on day 2 ( 0 vs $17 \%$ ), a significant reduction on day $3(\log$ rank $P$ value $=0.0219,31$ vs $62 \%)$, and reductions on day 4 (29 vs $31 \%$ ) and day 5 (0 vs $25 \%$ ).

\section{Necropsy}

Upon necropsy, animals treated with irinotecan (especially treated controls compared to SBI-gavaged animals) had an inflamed peritoneal cavity, particularly in the intestines and mesentery. SBI-administered animals also had less pronounced intestinal lymphatic nodules (Peyer's patches) than treated controls. While there were significant differences in organ weights at necropsy in all irinotecan-treated animals compared to untreated controls, post hoc analyses failed to identify specific differences associated with SBI administration.

\section{CBE and MBA-20}

There were no significant changes in all untreated, SBIgavaged groups compared to untreated controls; these groups have therefore been omitted from graphs to enhance visual clarity. Administration of SBI had no influence on any MBA-20 parameters.

Six hours after irinotecan treatment, there was an increase in the white cell count (WCC) in irinotecan-treated groups (Fig. 3a) that was largely driven by an increase in neutrophil numbers (Fig. 3b) and was less pronounced in groups given SBI, although this failed to reach significance. On days 2 and 4 post-treatment, WCCs in irinotecan-treated groups were significantly decreased compared to untreated controls $(P<0.0001)$, with SBI-gavaged groups showing a less pronounced, non-significant decrease at these time points (Fig. 3a). On day 6 post-treatment, however, WCCs in $250 \mathrm{mg} / \mathrm{kg}$ SBI-gavaged animals remained significantly lower than untreated and treated controls $(P=0.0141$ and $P=0.0018$, respectively, Holm-Sidak $t$ test), suggesting that WCCs in this group had failed to reach normal levels by the end of the study. Animals administered $500 \mathrm{mg} / \mathrm{kg}$ SBI also had lower WCC than untreated controls at the end of the study; however, this failed to reach significance (Fig. 3a).

At $6 \mathrm{~h}$ post-irinotecan treatment, there was a highly significant increase in neutrophils (as \% of total WCC) in irinotecan groups (Fig. 3b; $P<0.0001$ ); however, this increase was less pronounced in groups administered SBI (non-significant; Fig. 3b). A similar pattern was observed 2 days postirinotecan treatment. At 4 days post-treatment, all irinotecantreated animals showed a significant neutropenia when compared to untreated controls $(P<0.0001)$; however, post hoc analyses failed to identify differences between SBI-gavaged 
Table 1 Tissue damage scoring

\begin{tabular}{|c|c|c|}
\hline & Jejunum & Colon \\
\hline Crypt ablation (CA) & $\begin{array}{l}1=\text { markedly decreased length of crypts } \\
2=\text { complete ablation of crypts (ghost crypts) }\end{array}$ & $\begin{array}{l}1=\text { markedly decreased length of crypts } \\
2=\text { complete ablation of crypts (ghost crypts) }\end{array}$ \\
\hline Flattening of colonic folds (FC) & $\mathrm{N} / \mathrm{A}$ & $\begin{array}{l}1=\text { moderate flattening of folds and loss of surface } \\
\text { area } \\
2=\text { marked flattening of folds (loss of more than half of } \\
\text { normal folded area) }\end{array}$ \\
\hline Villous ablation/blunting (VA/B) & $\begin{array}{l}1=\text { villi }<\text { two thirds of normal length } \\
2=\text { villi }<\text { one third of normal length }\end{array}$ & NA \\
\hline Villous fusion (VF) & $\begin{array}{l}1=\text { one or two fused villi throughout tissue } \\
2=\text { majority of villi fused throughout tissue }\end{array}$ & N/A \\
\hline Mucosal ulcerations (MU) & $\begin{array}{l}1=\text { small superficial ulcerations } \\
2=\text { individual ulcerations (in total) involving } \\
\quad \text { approximately one third of intestinal circumference } \\
3=\text { large ulcerations involving more than half of the } \\
\text { intestinal circumference }\end{array}$ & $\begin{array}{l}1=\text { small superficial ulcerations } \\
2=\text { individual ulcerations (in total) involving } \\
\text { approximately one third of intestinal circumference } \\
3=\text { large ulcerations involving more than half of the } \\
\text { intestinal circumference }\end{array}$ \\
\hline $\begin{array}{l}\text { Inflammation (I) (increase in gut- } \\
\text { associated lymphoid tissue, GALT) }\end{array}$ & $\begin{array}{l}1=\text { widespread infiltrate of single WBCs } \\
2=\text { widespread infiltrate }+ \text { patches of WBCs discrete } \\
\text { from ulcerations }\end{array}$ & $\begin{array}{l}1=\text { widespread infiltrate of single WBCs } \\
2=\text { widespread infiltrate }+ \text { patches of WBCs discrete } \\
\text { from ulcerations }\end{array}$ \\
\hline Apoptosis (A) & $\begin{array}{l}1=\text { widespread distribution of single apoptotic cells in } \\
\text { crypts } \\
2=\text { patches of crypt apoptosis in crypts }\end{array}$ & $\begin{array}{l}1=\text { widespread distribution of single apoptotic cells in } \\
\text { crypts } \\
2=\text { patches of crypt apoptosis in crypts }\end{array}$ \\
\hline Tissue disorganisation (TD) & $\begin{array}{l}1=\text { disorientated crypts in some areas } \\
2=\text { disorientated crypts throughout tissue }\end{array}$ & $\begin{array}{l}1=\text { disorientated crypts in some areas } \\
2=\text { disorientated crypts throughout tissue }\end{array}$ \\
\hline Epithelial cell sloughing (ECS) & $\begin{array}{l}1=\text { discreet areas of lining epithelium sloughed into } \\
\text { lumen } \\
2=\text { majority of lining epithelial layer gone }\end{array}$ & $\begin{array}{l}1=\text { discreet areas of lining epithelium sloughed into } \\
\text { lumen } \\
2=\text { majority of lining epithelial layer gone }\end{array}$ \\
\hline Lymphatic congestion (LC) & $\begin{array}{l}1=\text { Dilated lymph vessels or cystic collections of } \\
\text { lymph } \\
2=\text { markedly dilated lymph vessels with large cystic } \\
\text { collections of lymph }\end{array}$ & $\begin{array}{l}1=\text { Dilated lymph vessels or cystic collections of } \\
\text { lymph } \\
2=\text { markedly dilated lymph vessels with large cystic } \\
\text { collections of lymph }\end{array}$ \\
\hline Blood vessel congestion (BVC) & $\begin{array}{l}1=\text { few individual vessels full of RBCs in discreet } \\
\text { areas } \\
2=\text { approximately half of blood vessels are full of } \\
\text { RBCs throughout the entire tissue } \\
3=\text { majority of visible blood vessels completely full of } \\
\text { RBCs, vessels appear distended }\end{array}$ & $\begin{array}{l}1=\text { few individual vessels full of RBCs in discreet } \\
\text { areas } \\
2=\text { approximately half of blood vessels are full of } \\
\text { RBCs throughout the entire tissue } \\
3=\text { majority of visible blood vessels completely full of } \\
\text { RBCs, vessels appear distended }\end{array}$ \\
\hline
\end{tabular}

animals and treated controls. After 6 days, neutrophil levels in all irinotecan-treated groups had recovered almost to normal levels; however, animals administered $500 \mathrm{mg} / \mathrm{kg}$ SBI were significantly closer to normal levels (untreated controls) than treated controls (Fig. 3b; $P=0.04959$, Holm Sidak $t$ test).

Conversely, at $6 \mathrm{~h}$ and 2 days post-irinotecan treatment, lymphocyte levels (as \% of total WCC) were significantly decreased in all irinotecan groups and significantly increased on day 4 compared to untreated controls (Fig. 3c; $P<0.0001$ ). These changes were less marked in SBI-gavaged groups (non-significant). This trend reached significance 6 days post-irinotecan treatment in both SBI groups versus treated controls (Fig. 3c; $P=0.0469, P=0.0035$, respectively, Holm Sidak $t$ test), where percentage of lymphocytes approached normal levels (untreated controls). Similarly to neutrophil levels, recovery of lymphocytes to normal levels was more pronounced in animals administered SBI compared to treated controls.

\section{Histology and tissue damage scoring}

There was a greater degree of irinotecan-induced damage in the colon than the jejunum (Fig. 4a, f), regardless of experimental group. In sections of jejunum from treated controls, villous atrophy, blunting and fusion was marked (Fig. 4b), and in colon and jejunum, cryptolysis was widespread, with severe attenuation of lining enterocytes, presence of apoptotic bodies in crypts, marked polymorphonuclear cell infiltrate within the lamina propria and accumulation of mucous and cellular debris within an enlarged lumen (Fig. 4b, d, g, i). Peyer's patches within the submucosa were often enlarged. Irinotecan-treated intestinal tissues also demonstrated an increased vascularity 
Fig. 1 a Bodyweight as percentage change from baseline. b Bodyweight in grams. Graphs represent data \pm SEM. Data was analysed via two-way ANOVA, with the Bonferroni post hoc test

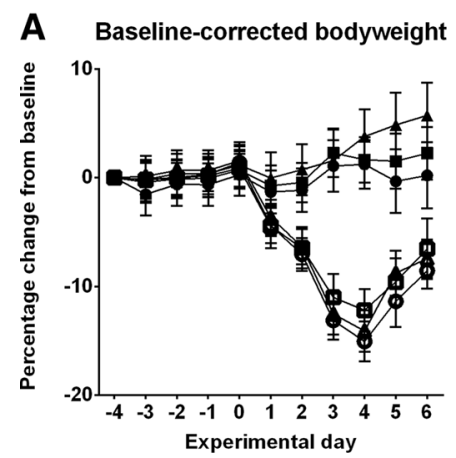

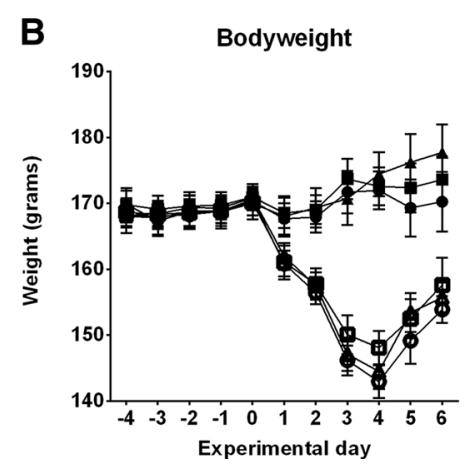

- $250 \mathrm{mg} / \mathrm{kg} \mathrm{SBI}$

- $250 \mathrm{mg} / \mathrm{kg} \mathrm{SBI}+\mid$ rinotecar

- $500 \mathrm{mg} / \mathrm{kg} \mathrm{SBI}$

a $500 \mathrm{mg} / \mathrm{kg} \mathrm{SBI}+\mid$ rinotecar

\ Untreated controls

$\Delta$ Treated controls within the lamina propria (Fig. 4b) and dilated lacteals, which were often congested with lymphatic fluid. Pathological changes had for the most part resolved by day 6 post-treatment; however, in some tissues, villous fusion and blunting, lymphatic dilation and inflammation were still observed (Fig. 4d, i).

Irinotecan-treated tissues from groups administered SBI at both 250 and $500 \mathrm{mg} / \mathrm{kg}$ displayed similar changes to those seen above; however, there was a visible decrease in crypt ablation (jejunum and colon; Fig. 4c, h) and villous ablation (jejunum, Fig. 4c, e) compared to treated controls (Fig. 4b, g). Overall, tissue architecture was preserved more noticeably in tissues derived from SBI-gavaged animals compared to treated controls (Fig. 4c, e, h, j). Presence of apoptotic cells within crypts at $6 \mathrm{~h}$ (Fig. 4c, h) and 2 days post-treatment was less prominent in jejunum and colon tissue derived from SBIadministered animals. Inflammatory cell infiltrate was also less pronounced.
Histopathological changes were then quantitated using the damage scoring system (Table 1). Untreated, SBIgavaged animals showed very low damage scores (0-1) similar to untreated controls and so have been omitted from graphs.

Administration of SBI resulted in significantly lower damage scores at all time points in jejunum and colon (Fig. 5; $P<0.0001$ ). This reduction in irinotecan-induced damage reached significance in $250 \mathrm{mg} / \mathrm{kg}$ SBI-gavaged animals compared to treated controls, at $6 \mathrm{~h}$ posttreatment in jejunum (Fig. 5a; $35.8 \pm 1.81$ vs $44.0 \pm 2.54$ ) and colon (Fig. 5b; 30.7 \pm 2.97 vs $43.6 \pm 2.83$ ), 2 days post-treatment in jejunum (Fig. 5a; $42.6 \pm 4.62$ vs $57.6 \pm$ 3.83 ) and colon (Fig. 5b; $25.6 \pm 1.75$ vs $36.3 \pm 2.80$ ) and at 6 days post-treatment in jejunum (Fig. 5a; 9.99 \pm 3.64 vs $21.6 \pm 2.06$ ) and colon (Fig. 5b; $13.6 \pm 2.61$ vs $26.4 \pm$ 2.37). Administration of $500 \mathrm{mg} / \mathrm{kg} \mathrm{SBI}$ also significantly reduced irinotecan-induced damage in the colon at $6 \mathrm{~h}$
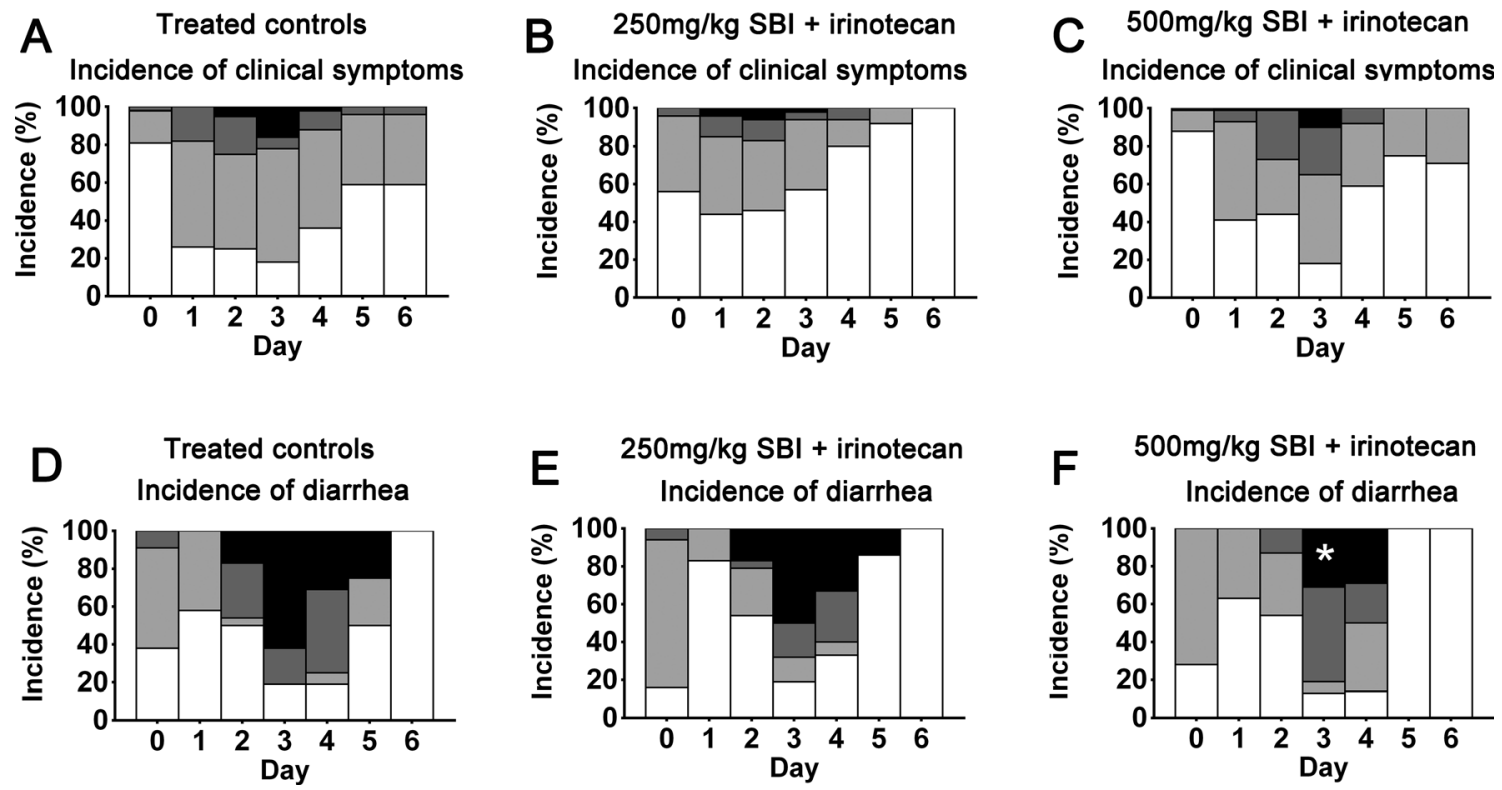

Fig. 2 Incidence of clinical signs of stress and diarrhoea. Graphs represent incidence of daily scores for each group, expressed as a percentage. Statistical significance for decreased grade 3 diarrhoea on

day 3 in animals treated with $500 \mathrm{mg} / \mathrm{kg}$ SBI and irinotecan vs irinotecan controls ( $\log$ rank $P$ value $=0.0219,31$ vs $62 \%$ ) is marked with an asterisk 


\section{A White cell count (WCC)}

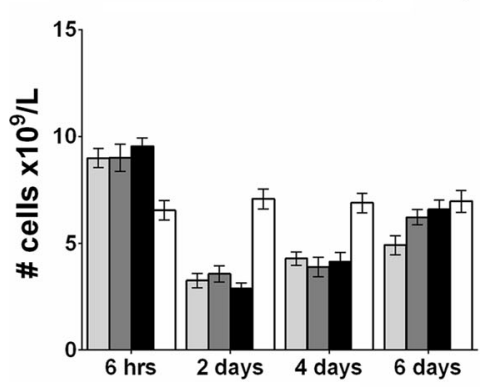

250mg/kg SBI + Irinotecan

\section{B Neutrophils (as \% of total WCC)}

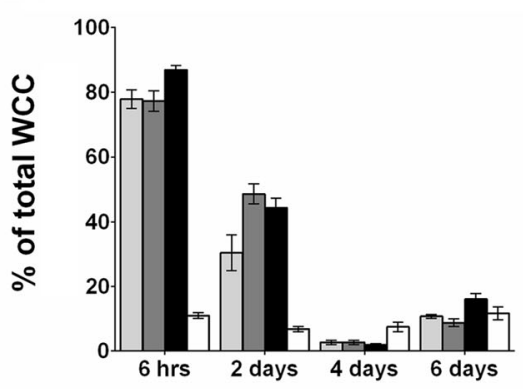

$500 \mathrm{mg} / \mathrm{kg} \mathrm{SBI}+\mid$ rinotecan
C Lymphocytes (as \% of total WCC)

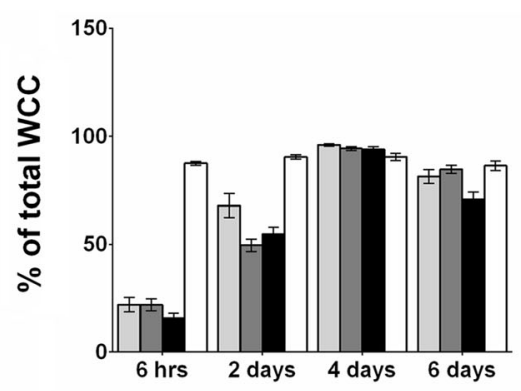

¿Untreated controls

Fig. 3 Total white cell count (WCC) and neutrophil and lymphocyte levels as a percentage of the total WCC. Graph represents data \pm SEM. Data was analysed via two-way ANOVA, with the Bonferroni post hoc analysis

post-treatment (Fig. 5b; 33.1 \pm 3.77 vs $43.6 \pm 2.83$; $P<0.0001$ ), 2 days post-treatment (Fig. 5b; $22.9 \pm 3.06$ vs $36.3 \pm 2.80$ ), and 4 days post-treatment (Fig. 5 b; 29.2 \pm 2.39 vs $37.1 \pm 2.41)$ and 6 days post-treatment in the jejunum (Fig. 5a; $13.6 \pm 2.83$ vs $21.6 \pm 2.06$ ) and colon (Fig. $5 b ; 18.1 \pm 3.13$ vs $26.4 \pm 2.37$ ).

\section{Alcian blue, periodic acid/Schiff staining of goblet cells}

Increased numbers of cavitated goblet cells have been associated with chemotherapy-induced gut injury [15]; in this study, however, there were no significant differences attributable to SBI treatment.
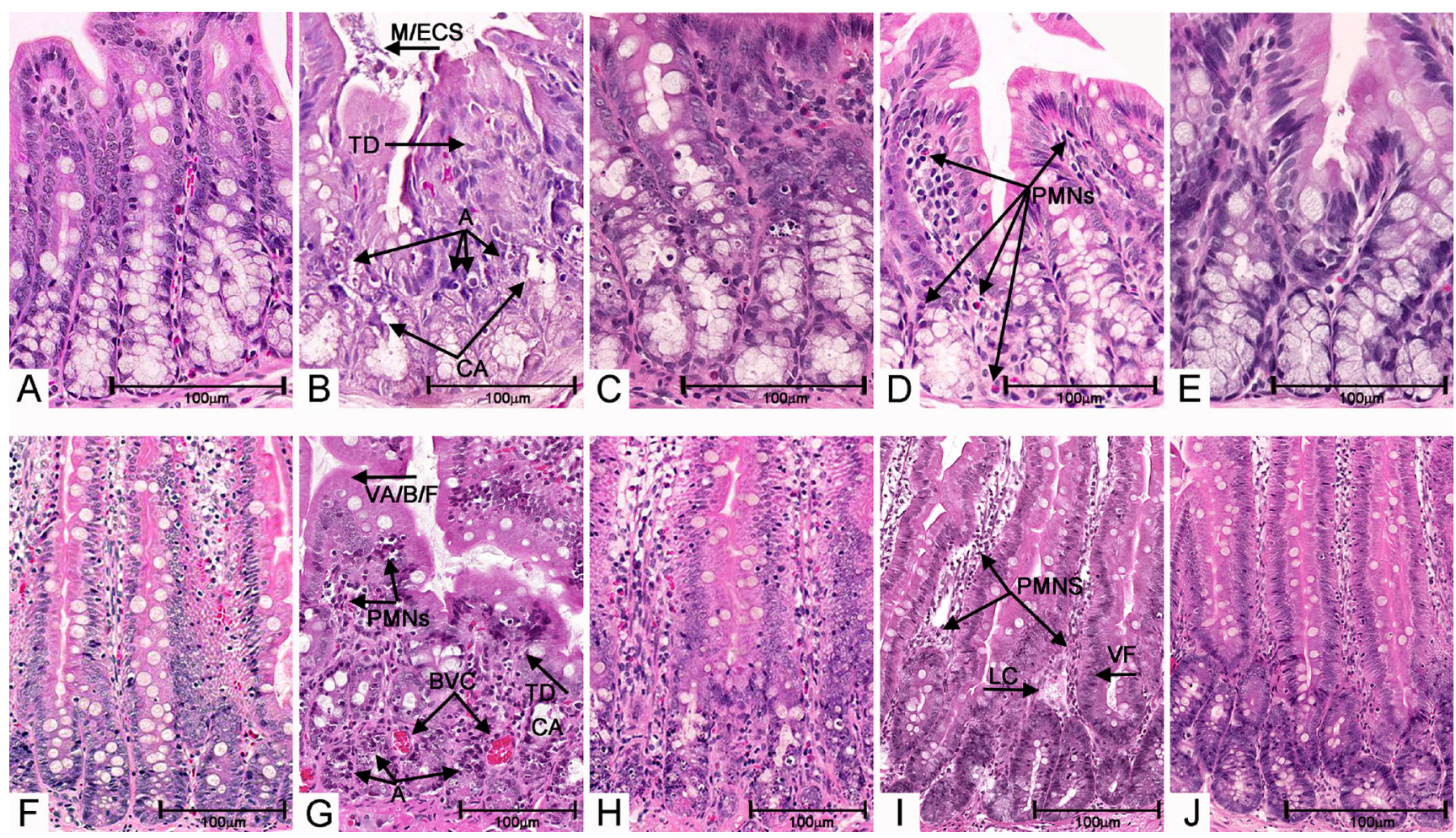

Fig. 4 H\&E-stained 4- $\mu \mathrm{m}$ sections of jejunum and colon. Bars represent $100 \mu \mathrm{m}$; all sections, original magnification $\times 100$. a Untreated colon. $\mathbf{b}$ Irinotecan-treated colon $6 \mathrm{~h}$ post-treatment. Arrows show apoptosis $(A)$, mucus/epithelial cell sloughing $(M / E C S)$, tissue disorganisation $(T D)$ and crypt ablation $(C A)$. c SBI-treated, irinotecan-treated colon, $6 \mathrm{~h}$ posttreatment. Note less TD, less CA, less A, than in b. d Irinotecan-treated colon 6 days post-treatment. Arrows show polymorphonuclear cells (PMNs) within the lamina propria. e SBI-treated, irinotecan-treated colon, 6 days post-treatment. Note less PMN infiltrate than in $\mathbf{d} . \mathbf{f}$

Untreated jejunum. g Irinotecan-treated jejunum $6 \mathrm{~h}$ post-treatment. Arrows show villous ablation/blunting/fusion $(V A / B / F)$, PMNs, A, CA, $\mathrm{TD}$ and blood vessel congestion $(B V C)$. h SBI-treated, irinotecan-treated jejunum, $6 \mathrm{~h}$ post-treatment. Note less TD, less VA/B/F, less A, less BVC than in $\mathbf{g}$. i Irinotecan-treated jejunum 6 days post-treatment. Arrows show PMN infiltrate, villous fusion $(V F)$ and lymphatic congestion $(L C)$. j SBI-treated, irinotecan-treated jejunum, 6 days post-treatment. Note higher degree of tissue organisation, no LC or VF, and slightly less $\mathrm{PMN}$ infiltrate in the lamina propria 
Fig. 5 Tissue damage scores. Graph represents data \pm SEM. Data was analysed via two-way ANOVA, with the Bonferroni post hoc analysis. Asterisks represent significance when compared to treated controls $(P<0.0001)$
A

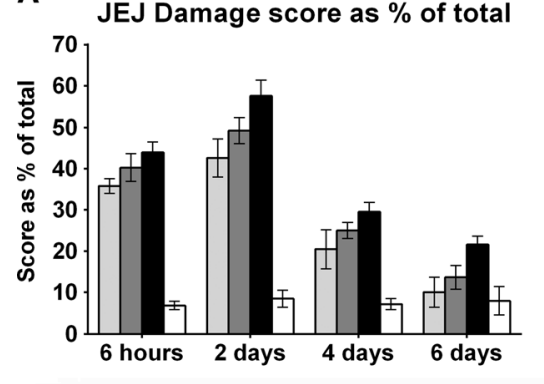

\section{B}

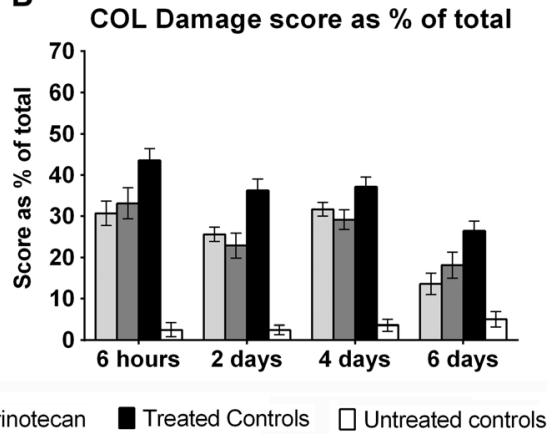

\section{Morphometry}

In the jejunum, villous area of all irinotecan-treated animals was significantly increased on day 6 post-treatment compared to untreated controls $(P<0.0001$; due to rebound hyperplasia); however, SBI administration was not associated with any significant differences between groups.

\section{Immunohistochemistry to assess proliferation and apoptosis}

Levels of proliferating and apoptotic cells were consistent with irinotecan treatment; however, analysis failed to highlight differences between SBI-gavaged and saline-treated animals in either the jejunum or colon.

\section{Discussion}

In the current study, twice daily administration of SBI was well-tolerated and resulted in reduction in the incidence, severity and duration of irinotecan-induced clinical signs of stress and diarrhoea, as well as a significant reduction in histopathological damage in the intestines. There is evidence that the basis for these observations is modulation of the inflammatory response associated with irinotecan-induced mucositis. The results herein are consistent with results observed in similar animal intestinal studies, where SBI was utilized, and also show similar symptom reduction as seen in patient studies of enteropathies managed with SBI.

Since chemotherapy-induced GI mucositis (CIGM) has a similar etiology and symptom profile to intestinal disorders such as IBS-D and HIV-associated enteropathy, it is reasonable to suggest that patients suffering from CIGM would show similarly improved symptoms with SBI. The animal model used in this study has been well established and has many similarities to the patient setting; thus, we postulated that administration of SBI would manage CIGM.

In a pilot study of 66 patients by Wilson et al. [8], daily administration of $10 \mathrm{~g}$ of SBI over a period of 6 weeks significantly reduced the severity and frequency of symptoms of
IBS-D, such as abdominal pain, stool frequency, loose stools, bloating, flatulence and urgency, compared to placebo (soy protein isolate). Similarly, in a study of eight patients with HIV-associated enteropathy by Asmuth [10], twice daily administration of $2.5 \mathrm{~g}$ SBI for 8 weeks resulted in reduced bowel movements and improved stool consistency in all patients. In the current study, irinotecan-treated rats gavaged with human equivalent doses of SBI also showed a significant reduction in the incidence, severity and duration of mucositisassociated symptoms, such as diarrhoea.

Since the animals in this model were administered SBI 4 days prior to irinotecan treatment, it would be interesting to see whether a longer period of pre-treatment SBI administration would further improve diarrhoea and clinical symptoms of stress. Such preparatory dosing would also be possible in patients with CIGM (if SBI was given before irinotecan administration); however, since patients with other enteropathies present with these conditions before SBI administration would be possible, benefits of preparatory dosing in these conditions will remain unknown. A future animal study to determine whether dosing with SBI at the onset of mucositis symptoms (without preparatory dosing) is able to achieve the same results as the current study would provide useful information on the value of pre-treatment and determine whether protective effects of SBI are transient or cumulative.

The lack of changes in bodyweights, organ weights, intestinal goblet cells, morphometry, apoptosis and proliferation suggest that SBI-associated attenuation of the clinical symptoms of mucositis is not dependent upon increased cell proliferation and tissue growth as is observed after treatment with growth factors designed to alleviate mucositis $[16,17]$. Similar findings were made in rotavirus-infected pigs [18], where SBI administration did not significantly increase weight gain or alter tissue morphometry, and in weaning piglets, where SBI administration showed few changes to intestinal morphometry, and in fact resulted in lower small intestinal weight over the treatment period [19].

SBI is high in glutamic acid, which is converted to glutamine. Studies have shown that free glutamine is an essential amino acid required during times of catabolic stress, such as injury or disease, and is a preferential energy source not only 
for enterocytes but also for rapidly proliferating immune cells $[20,21]$. It is thus linked to the maintenance of intestinal barrier function and cell differentiation and may contribute to the positive effects of SBI as observed in this study, where histopathological analyses showed that tissues from animals administered SBI were more likely to retain proper architecture and an intact epithelial layer.

One hypothesis for the positive effects of SBI in enteropathic conditions is the modulation of intestinal immune function in gut-associated lymphoid tissue (GALT) and reduced levels of pro-inflammatory cytokines [7, 22, 23]. Oral administration of spray-dried plasma proteins was associated with a decreased level of inflammatory cytokines in organised (Peyer's patches) and diffuse (lymphocytes in lamina propria) GALT of the ileum and colon in weaning piglets, which show similar symptoms to patients suffering from GI mucositis, including malabsorption, diarrhoea and weight loss associated with increased gut permeability [7]. Results obtained in the current study reflect these findings, as levels of circulating and mucosal neutrophils and lymphocytes (diffuse GALT) in irinotecan-treated animals receiving SBI were lower than those in treated controls. Anecdotal evidence of less pronounced intestinal lymphatic nodules (organised GALT) and less inflamed peritoneal cavities during necropsy also supports this. Further studies to assess tissue levels of proinflammatory cytokines are currently underway.

Analysis of histopathological damage showed significantly lower damage scores in both colon and jejunum of irinotecantreated animals that had received both 250 and $500 \mathrm{mg} / \mathrm{kg}$ SBI, compared to those that had not. The density of lymphoid cells present in the lamina propria was decreased in gut tissues from animals gavaged with SBI, which was reflected in comparatively lower total white cell counts and percentages of neutrophils and lymphocytes in circulating blood. Reduced damage scores were most pronounced 2 and 4 days posttreatment in tissues from animals receiving SBI compared to treated controls. This also supports the potential antiinflammatory role of SBI, suggesting that preparatory dosing prior to irinotecan treatment is not enough to stop the initial damage but helps to attenuate the induced inflammatory state which further drives the damage.

Low-grade inflammation, either idiopathic or injury-induced, is associated with increased epithelial permeability in the gut due to degradation of occludin within tight junctions [24]. Transepithelial bacterial translocation is then more likely to occur, thus increasing lipopolysaccharide exposure to the GALT, which then further drives the process through the release of pro-inflammatory cytokines, giving rise to clinical symptoms such as diarrhoea, malabsorption and subsequent weight loss. The process is thought to underpin chronic diseases such as IBS-D [8] and HIV-associated enteropathy [10], and physiologically stressful conditions such as malnutrition [6] and weaning [25], and is often accompanied by changes to the microbiota, which may further compound the inflammatory process. Gastrointestinal mucositis initiated by cancer therapy (chemotherapy, radiotherapy and targeted therapy) occurs through direct damage to gut epithelium and creation of reactive oxygen species; however, the subsequent mechanisms of inflammation, increased gut permeability and clinical symptoms are similar to the abovementioned conditions. It has been shown that IgG in SBI binds lipopolysaccharide from bacterial cell walls, thus protecting mucosal surfaces from bacterial antigenic exposure [26, 27]. Similar binding effects have also been demonstrated for endotoxins [22, 28, 23] and rotavirus [18], further underpinning the importance of SBI in management of enteropathies [29, 30]. Additional studies to explore the role of SBI in attenuating the intestinal inflammatory response and possible maintenance of the healthy microbiota in this animal model are currently underway.

The results from this study demonstrate that SBI shows significant promise in the management of chemotherapyinduced GI mucositis in an animal model. Positive effects of SBI in the management other enteropathies with similar symptom profiles in patients have also been demonstrated, perhaps paving the way for similar use of SBI in the supportive care of treatment-induced mucositis. Further studies to underpin exact mechanisms of action and effects on solid tumours are required, however, as well as comprehensive analyses of proinflammatory cytokines within gut tissue and microbiome alterations.

Conflicts of interest Funding to complete the studies herein was administered as an unrestricted educational grant from Entera Health Inc. to the University of Adelaide. The role of the funding source was to provide the study drug, EnteraGam, and support to complete the animal experiment. The chief investigators named on the grant were Prof. Keefe and Dr. Bateman. No honorarium was received by any author.

Open Access This article is distributed under the terms of the Creative Commons Attribution-NonCommercial 4.0 International License (http:// creativecommons.org/licenses/by-nc/4.0/), which permits any noncommercial use, distribution, and reproduction in any medium, provided you give appropriate credit to the original author(s) and the source, provide a link to the Creative Commons license, and indicate if changes were made.

\section{References}

1. Keefe DM, Sonis ST, Bowen JM (2008) Emerging drugs for chemotherapy-induced mucositis. Expert Opin Emerg Drugs 13: 511-522

2. Stringer AM, Gibson RJ, Bowen JM, Keefe DMK (2009) Chemotherapy-induced modifications to gastrointestinal microflora: evidence and implications of change current drug metabolism 10: $79-83$

3. Thorpe DW, Stringer AM, Gibson RJ (2013) Chemotherapyinduced mucositis: the role of the gastrointestinal microbiome and toll-like receptors. Exp Biol Med (Maywood) 238:1-6 
4. Gibson RJ, Keefe DM, Lalla RV, Bateman E, Blijlevens N, Fijlstra M, King EE, Stringer AM, van der Velden WJ, Yazbeck R, Elad S, Bowen JM (2012) Systematic review of agents for the management of gastrointestinal mucositis in cancer patients. Support Care Cancer 21:313-326

5. Guarino A, Canani RB, Russo S, Albano F, Canani MB, Ruggeri FM, Donelli G, Rubino A (1994) Oral immunoglobulins for treatment of acute rotaviral gastroenteritis. Pediatrics 93:12-16

6. Lembcke JL, Peerson JM, Brown KH (1997) Acceptability, safety, and digestibility of spray-dried bovine serum added to diets of recovering malnourished children. J Pediatr Gastroenterol Nutr 25:381-384

7. Peace RM, Campbell J, Polo J, Crenshaw J, Russell L, Moeser A (2011) Spray-dried porcine plasma influences intestinal barrier function, inflammation, and diarrhea in weaned pigs. J Nutr 141: 1312-1317

8. Wilson D, Evans M, Weaver E, Shaw AL, Klein GL (2013) Evaluation of serum-derived bovine immunoglobulin protein isolate in subjects with diarrhea-predominant irritable bowel syndrome clinical medicine insights. Gastroenterology 6:49-60

9. Entera Health I (2014) EnteraGam - full prescribing information. In: Editor (ed)^(eds) Book EnteraGam - full prescribing information, City

10. Asmuth DM, Ma ZM, Albanese A, Sandler NG, Devaraj S, Knight TH, Flynn NM, Yotter T, Garcia JC, Tsuchida E, Wu TT, Douek DC, Miller CJ (2013) Oral serum-derived bovine immunoglobulin improves duodenal immune reconstitution and absorption function in patients with HIV enteropathy. AIDS 27:2207-2217

11. Gibson RJ, Bowen JM, Inglis MR, Cummins AG, Keefe DM (2003) Irinotecan causes severe small intestinal damage, as well as colonic damage, in the rat with implanted breast cancer. $\mathrm{J}$ Gastroenterol Hepatol 18:1095-1100

12. Stringer AM, Gibson RJ, Logan RM, Bowen JM, Yeoh ASJ, Keefe DMK (2006) Chemotherapy-induced changes in mucin secretion and composition. J Gastroen Hepatol 21:A266-A266

13. Bowen JM, Gibson RJ, Keefe DM, Cummins AG (2005) Cytotoxic chemotherapy upregulates pro-apoptotic Bax and Bak in the small intestine of rats and humans. Pathology 37:56-62

14. Keefe DM, Brealey J, Goland GJ, Cummins AG (2000) Chemotherapy for cancer causes apoptosis that precedes hypoplasia in crypts of the small intestine in humans. Gut 47:632-637

15. Bowen JM, Stringer AM, Gibson RJ, Yeoh AS, Hannam S, Keefe DM (2007) VSL\#3 probiotic treatment reduces chemotherapyinduced diarrhea and weight loss. Cancer Biol Ther 6:1449-1454

16. Mayo B, Bateman E, Stringer A, Plews E, Wignall A, Wozniak B, White I, Pietra C, Cantoreggi S, Keefe D (2014) The new selective GLP-2 receptor agonist, Elsiglutide, improved irinotecan-induced diarrhoea and mucositis in the rat. Support Care Cancer 22:S123

17. Mayo B, Stringer A, Bateman E, Bowen J, Pietra C, Cantoreggi S, Keefe D (2014) Apoptosis, proliferation and inflammation are improved after treatment with the new selective GLP-2 receptor agonist, Elsiglutide, in a rat model of irinotecan-induced mucositis. Support Care Cancer 22:S123

18. Corl BA, Harrell RJ, Moon HK, Phillips O, Weaver EM, Campbell JM, Arthington JD, Odle J (2007) Effect of animal plasma proteins on intestinal damage and recovery of neonatal pigs infected with rotavirus. J Nutr Biochem 18:778-784

19. Jiang R, Chang X, Stoll B, Fan MZ, Arthington J, Weaver E, Campbell J, Burrin DG (2000) Dietary plasma protein reduces small intestinal growth and lamina propria cell density in early weaned pigs. J Nutr 130:21-26

20. Blijlevens NM, Donnelly JP, Naber AH, Schattenberg AV, DePauw $\mathrm{BE}$ (2005) A randomised, double-blinded, placebo-controlled, pilot study of parenteral glutamine for allogeneic stem cell transplant patients. Support Care Cancer 13:790-796

21. Sukhotnik I, Mogilner JG, Karry R, Shamian B, Lurie M, Kokhanovsky N, Ure BM, Coran AG (2009) Effect of oral glutamine on enterocyte turnover during methotrexate-induced mucositis in rats. Digestion 79:5-13

22. Perez-Bosque A, Amat C, Polo J, Campbell JM, Crenshaw J, Russell L, Moreto M (2006) Spray-dried animal plasma prevents the effects of Staphylococcus aureus enterotoxin B on intestinal barrier function in weaned rats. J Nutr 136:2838-2843

23. Perez-Bosque A, Miro L, Polo J, Russell L, Campbell J, Weaver E, Crenshaw J, Moreto M (2008) Dietary plasma proteins modulate the immune response of diffuse gut-associated lymphoid tissue in rats challenged with Staphylococcus aureus enterotoxin. B J Nutr 138:533-537

24. Wardill HR, Bowen JM, Al-Dasooqi N, Sultani M, Bateman E, Stansborough R, Shirren J, Gibson RJ (2014) Irinotecan disrupts tight junction proteins within the gut: implications for chemotherapy-induced gut toxicity. Cancer Biol Ther 15:236-244

25. Bosi P, Casini L, Finamore A, Cremokolini C, Merialdi G, Trevisi P, Nobili F, Mengheri E (2004) Spray-dried plasma improves growth performance and reduces inflammatory status of weaned pigs challenged with enterotoxigenic Escherichia coli K88. J Anim Sci 82: 1764-1772

26. Navarro A, Eslava C, Garcia de la Torre G, Leon LA, Licona D, Leon L, Zarco LA, Cravioto A (2007) Common epitopes in LPS of different Enterobacteriaceae are associated with an immune response against Escherichia coli $\mathrm{O} 157$ in bovine serum samples. J Med Microbiol 56:1447-1454

27. Konadu E, Robbins JB, Shiloach J, Bryla DA, Szu SC (1994) Preparation, characterization, and immunological properties in mice of Escherichia coli $\mathrm{O} 157 \mathrm{O}$-specific polysaccharide-protein conjugate vaccines. Infect Immun 62:5048-5054

28. Weaver EM, Klein GL, DeVries BK, Maas K, Shaw AL (2013) Endotoxin neutralization activity (ENA) of bovine plasma and bovine immunoglobulin (IgG)-rich fractions as compared to human plasma. FASEB J 27:1079.1058

29. Currie CG, McCallum K, Poxton IR (2001) Mucosal and systemic antibody responses to the lipopolysaccharide of Escherichia coli O157 in health and disease. J Med Microbiol 50:345-354

30. Pasternak BA, D’Mello S, Jurickova II, Han X, Willson T, Flick L, Petiniot L, Uozumi N, Divanovic S, Traurnicht A, Bonkowski E, Kugathasan S, Karp CL, Denson LA (2010) Lipopolysaccharide exposure is linked to activation of the acute phase response and growth failure in pediatric Crohn's disease and murine colitis. Inflamm Bowel Dis 16:856-869 